\title{
THE EFFECT OF MICRO/NANOSCALE STRUCTURES ON CHF ENHANCEMENT
}

\author{
HO SEON AHN ${ }^{1}$ and MOO HWAN KIM ${ }^{* 2}$ \\ ${ }^{1}$ Department of Mechanical Engineering, POSTECH, Pohang, Republic of Korea \\ ${ }^{2}$ Division of Advanced Nuclear Engineering, POSTECH, Pohang, Republic of Korea \\ "Corresponding author. E-mail : mhkim@postech.ac.kr
}

Received April 25, 2011

Recently, many research studies have investigated the enormous critical heat flux (CHF) enhancement caused by nanofluids during pool boiling and flow boiling. One of the main reasons for this enhancement is nanoparticle deposition on the heated surface. However, in real applications, nanofluids create many problems when used as working fluids because of sedimentation and aggregation. Therefore, artificial surfaces on silicon and metal have been developed to create an effect similar to that of nanoparticle deposition. These modified surfaces have proved capable of greatly increasing the CHF during pool boiling, and good results have also been observed during flow boiling. In this study, we demonstrate that the wetting ability of a surface, i.e., wettability, and the liquid spreading ability (hydrophilic surface property), are key parameters for increasing the CHF during both pool and flow boiling. We also demonstrate that when the fuel surface in nuclear power plants is modified in a similar manner, it has the same effect, producing a large CHF enhancement.

KEYWORDS : Critical Heat Flux, Pool Boiling, Flow Boiling, Wettability, Spreading, Nanostructure, Microstructure, Surface Modification

\section{INTRODUCTION}

The problem of cooling reactors has become increasingly critical in the nuclear industry. The most effective way to cool a nuclear power plant running at high temperatures is through boiling heat transfer, which exploits the latent heat of vaporization during the phase change from liquid to gas. However, boiling heat transfer has an inherent limitation, namely the critical heat flux (CHF), which is the maximum heat flux at which boiling heat transfer has a high cooling efficiency. When a surface reaches the CHF, it becomes coated with a vapor film that interferes with the contact between the surface and the ambient liquid, decreasing the heat transfer efficiency. The system temperature increases, and failure occurs if the temperature exceeds the thermal limits of the system's constituent materials. For this reason, every system incorporates a safety margin by running at a heat flux much lower than the CHF, which reduces the system efficiency. This compromise between safety and efficiency is an important problem in the nuclear industry.

\section{Nanofluids in Pool Boiling}

Nanofluids are engineered heat-transfer fluids consisting of nanometer-sized particles (nanoparticles) dispersed in a base liquid. These fluids have been examined in various thermal engineering fields since Choi [1] began studying nanosized particles well dispersed in engineered fluids. Adding tiny amounts $(<0.001 \%$ by volume) of alumina nanoparticles to a conventional cooling liquid can increase the CHF by $200 \%$ [2]. During pool boiling, the same magnitude of CHF increase observed with a nanofluid can also occur when a nanoparticle-fouled surface is submerged, even in pure water [3]. This result suggests that the CHF increase in nanofluids is caused by the surface characteristics altered due to the surface nanoparticle deposition during boiling. Similar results have also been obtained by Golobic and Ferjancic [4]. Therefore, changes in interfacial parameters due to nanoparticle fouling could be a key factor in the significant CHF increase caused by nanofluids.

Nanoparticle-fouled surfaces have significantly greater wettability than do bare surfaces, as can be determined by the reduction in the measured static contact angle of droplets [5]. This observation was based on a review of the prevalent $\mathrm{CHF}$ theories, which state that the improved wettability caused by the nanoparticle layer can be used to predict CHF enhancement. In pool-boiling experiments with water-based and alcohol-based nanofluids on a plain heated surface, the deposition of nanoparticles on the boiling surface changes the surface microstructure and physicochemical properties $[6,7]$. Such changes in the heating surface significantly influence the boiling phenomena by changing the nucleation site density, bubble 
departure diameter, bubble frequency, and evaporation of the microlayer and macrolayer beneath the growing bubbles. Kim and Kim [8] performed a capillary wicking measurement of a nanoparticle-fouled thin heater. They postulated that the capillarity of the heater due to nanoparticle deposition supplied water to dry spots near the CHF, delaying the CHF significantly. However, the concentrations of nanoparticles in a nanofluid can change due to agglomeration and settling, which change limits the usefulness of nanofluids in cooling systems.

\section{Surface Modifications to Enhance the CHF During Pool Boiling}

Many studies have been conducted to investigate $\mathrm{CHF}$ enhancement, and various approaches have been examined to delay the $\mathrm{CHF}$ and to understand the $\mathrm{CHF}$ phenomenon itself. Several effective surface-modification approaches have been studied. These can be narrowed down to roughening the surface, changing the wettability or surface energy, and modifying the surface geometry by machining or applying foreign materials. Previous research on these CHF-enhancing approaches is reviewed here. Because most of these studies have considered several approaches simultaneously, a general description of each approach will be given first, and details about each applicable study will follow, ordered by the year each study was performed. Generally, studies oriented toward nuclear applications have used water as the working fluid, and studies oriented towards electronic chip cooling have used dielectric refrigerant as the working fluid.

Nanofluid experiments have indicated that the heating surface characteristics significantly affect the nucleate boiling phenomena. Surface wettability can be increased by several methods. Because wetting is governed by the surface energy and surface morphology, surface modification methods can be based on either ultraviolet irradiation or thermal oxidation. Ultraviolet irradiation uses high-energy radiation to modify the surface energy of the materials; it can even produce a super hydrophilic (contact angle $<5^{\circ}$ ) state. This method increases both the wettability and the heat flux of the materials [9], but it is not practical for industrial use because the effect is not permanent. Thermal oxidation is a simple and easy method of modifying the surface energy to increase the wettability because metal oxide is more hydrophilic than pure metal. Thermal oxidation has been used to make hydrophilic heater surfaces [10]. However, simple thermal oxidation has certain limitations and is not capable of producing highly wettable surfaces.

The following researchers have used artificial micro/ nanoscale surfaces to increase the CHF. Kim et al. [11] reported that flat surfaces and surfaces with micrometersize (microscale), nanometer-size (nanoscale), and both microscale and nanoscale (micro/nanoscale) structures created on a silicon wafer using microelectromechanical system (MEMS) techniques have different $\mathrm{CHF}$ values; the effects of surface structure and surface wettability were dominant factors affecting this change. The liquidspreading effect of nanoscale rods on a micro/nanoscale surface changed the surface wettability and produced a greater increase in the CHF than did other factors. Ahn et al. [12] used zircaloy-4 (Zerlo, zirconium alloy) as a test material for pool-boiling CHF experiments. Their results are valuable because zirconium alloy is often used as cladding for nuclear fuel rods. They tested whether the $\mathrm{CHF}$ on a zirconium alloy surface can be increased using non-traditional metals such as copper or stainless steel and looked at various methods of treating the zirconium alloy with the aim of achieving a more wettable surface.

\section{CHF Enhancement in Flow Boiling}

Recently, several studies were conducted to increase the CHF during flow boiling. Surfactant water-based solution has been shown to increase the CHF during flow boiling [13]. The wettability of the heating surface decreased due to changes in the surface tension of the working fluid, not due to the surface characteristics. Ahn et al. [14, 15] investigated aqueous nanofluids with a $0.01 \%$ concentration of alumina nanoparticles; the $\mathrm{CHF}$ was enhanced under forced convective flow conditions compared with that observed using pure water. They conducted experiments with varying flow velocities, starting from $0 \mathrm{~m} / \mathrm{s}$ (effectively pool boiling) up to $4 \mathrm{~m} / \mathrm{s}$. A CHF enhancement of $50 \%$ was found at $0 \mathrm{~m} / \mathrm{s}$, consistent with the pool boiling reported by previous researchers [3-5]. After the boiling experiments, Ahn et al., $[14,15]$ used a scanning electron microscope (SEM) to examine the heater surfaces, and they measured the contact angle. They determined that the CHF enhancement was mainly due to nanoparticle deposition on the heater surface during vigorous boiling. This deposition caused the contact angle to decrease from $65^{\circ}$ to about $12^{\circ}$, illustrating an evident enhancement in the wettability of the heater surface. These experiments illustrate that nanofluids cause significant $\mathrm{CHF}$ enhancement under both pool-boiling and convective flow-boiling conditions.

\section{RECENT NANOFLUID EXPERIMENTS}

Using nanofluids as working fluids in boiling applications can greatly increase the CHF [1-3]. In this study, we performed nanofluid experiments using several types of experimental apparatus to examine the cause of the increased CHF in detail.

\subsection{Pool Boiling Nanofluid Experiments}

The CHF has been shown to increase in pool-boiling nanofluid experiments using various concentrations of $\mathrm{TiO}_{2}$ or $\mathrm{Al}_{2} \mathrm{O}_{3}$ nanoparticles on $\mathrm{Ni}-\mathrm{Cr}$ wire under 
atmospheric conditions [3, 5, 8]. Scanning electron microscopy (SEM) has revealed that nanoparticle coatings are generated on the wire surfaces during the pool boiling (Fig. 1). The similarity between the CHF of nanoparticlefouled surfaces in pure water and that of a clean surface in nanofluids (Fig. 2) suggests that the CHF of nanofluids

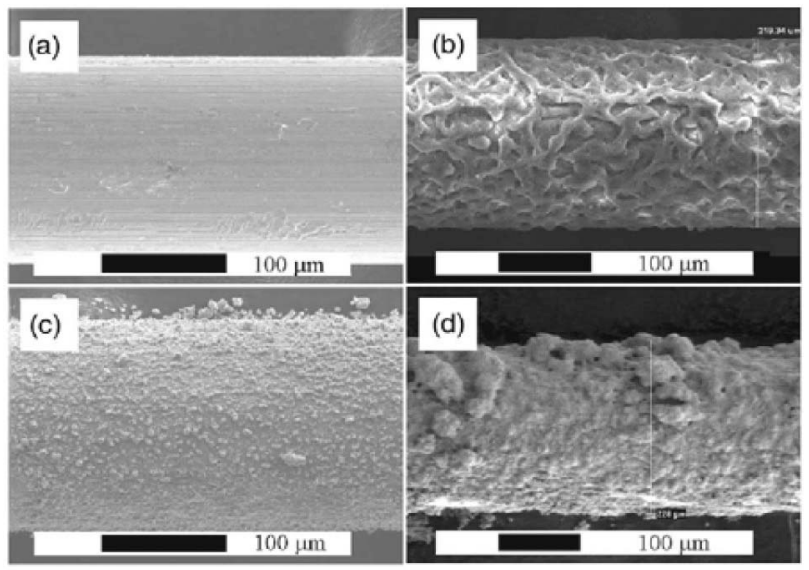

Fig. 1. SEM Images of (a) Bare Wire, (b) $\mathrm{TiO}_{2}$, (c) $\mathrm{SiO}_{2}$ and (d) Ag Nanoparticles Deposited on wire after Boiling [3].
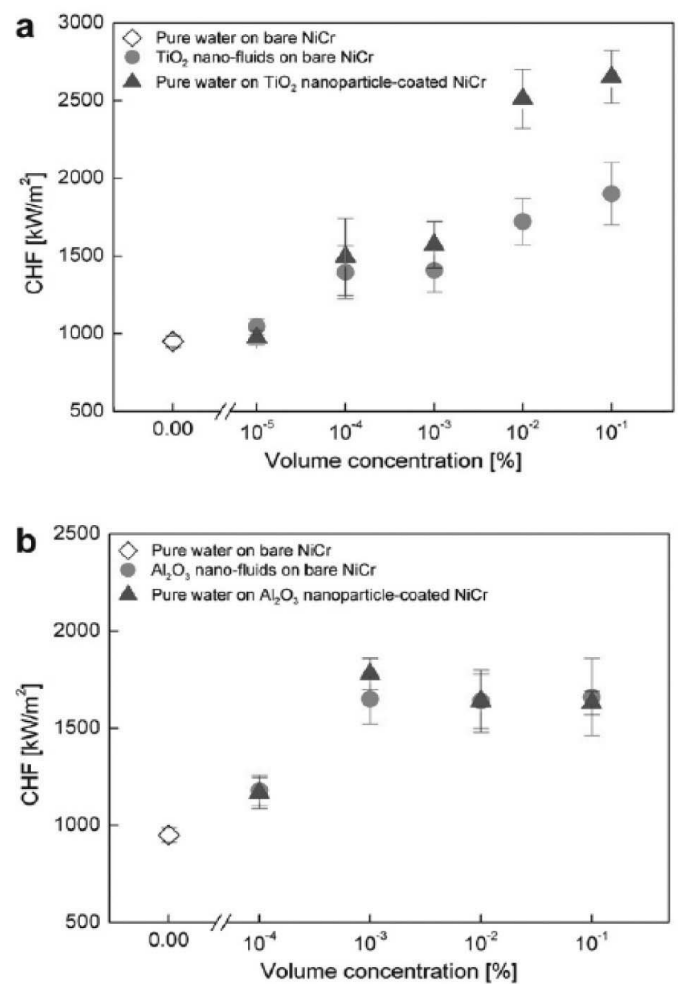

Fig. 2. Comparison of CHF Increases of Nanofluids on a Bare Heater and of Pure Water on Nanoparticles-coated Heaters: (a) $\mathrm{TiO}_{2}$; (b) $\mathrm{Al}_{2} \mathrm{O}_{3}[5]$. is related to the modification of surfaces immersed in the fluid $[3,5,8]$.

A previous study examined plate pool boiling to develop an understanding of the dominant factors that affect the CHF. In these plate-boiling experiments, thermal heating was used to preclude any interaction between the nanoparticles and the electrical field. Detailed information about the plate pool-boiling facility and the test samples can be found in Reference [16]. The results of the plate pool-boiling experiments confirm that nanofluids can significantly increase the $\mathrm{CHF}$ and that surface modifications due to nanoparticle deposition result in the same magnitude of CHF increase in pure water as in nanofluids. These results correspond well with previous experiments (Fig. 2,3 ). When analyzing the CHF on a surface modified by nanoparticle fouling, the recoil force is regarded as the factor that most strongly influences the CHF enhancement. After visualizing the dynamic wetting motion of an evaporating water droplet (Figs. 4 and 5), the authors conjectured that the nanoparticle layer increased the stability of the evaporating microlayer underneath a bubble growing on a heated surface. Thus, the irreversible growth of a hot/dry spot was inhibited, even at superheated wall temperatures, resulting in the $\mathrm{CHF}$ increase observed when boiling nanofluids [16]. Through comparisons of the CHF values for nanofluids on a clean surface and the values obtained for pure water on a nanoparticle-fouled surface, the authors demonstrated that the main cause for the CHF enhancement in nanofluids was the nanoparticle deposition on the surface. Subsequent to the boiling experiments, wetting tests of a water droplet revealed that the high surface wettability on the nanoparticle layer improved the stability of the meniscus evaporating on the heated surface. The critical wall superheat at which the evaporating liquid meniscus suddenly receded due to the evaporation recoil force was about $50^{\circ} \mathrm{C}$ on the clean surface and at least $100^{\circ} \mathrm{C}$ on the nanoparticle-fouled surface. This suggests that the evaporating microlayer with its improved stability against the evaporating recoil force can continue to dissipate the thermal energy of the heated surface at the higher surface temperature, inhibiting the irreversible growth of a hot/dry spot. Therefore, a model based on the hot/dry spot theory combined with the micro hydrodynamics of a thin liquid meniscus appears to provide a plausible explanation for the physical mechanism of nanofluid CHF enhancement.

\subsection{Flow-boiling Nanofluid Experiments}

Previous nucleate boiling experiments in nanofluids have reported an increased CHF during pool boiling due to the surfaces modified by nanoparticle fouling. Considering the importance of flow-boiling heat transfer in various practical applications, an experimental study of the CHF enhancement of nanofluids during convective flow conditions has been performed [14]. A rectangular channel (10 $\mathrm{mm}$ wide, $5 \mathrm{~mm}$ deep) was used to confine the flow. 

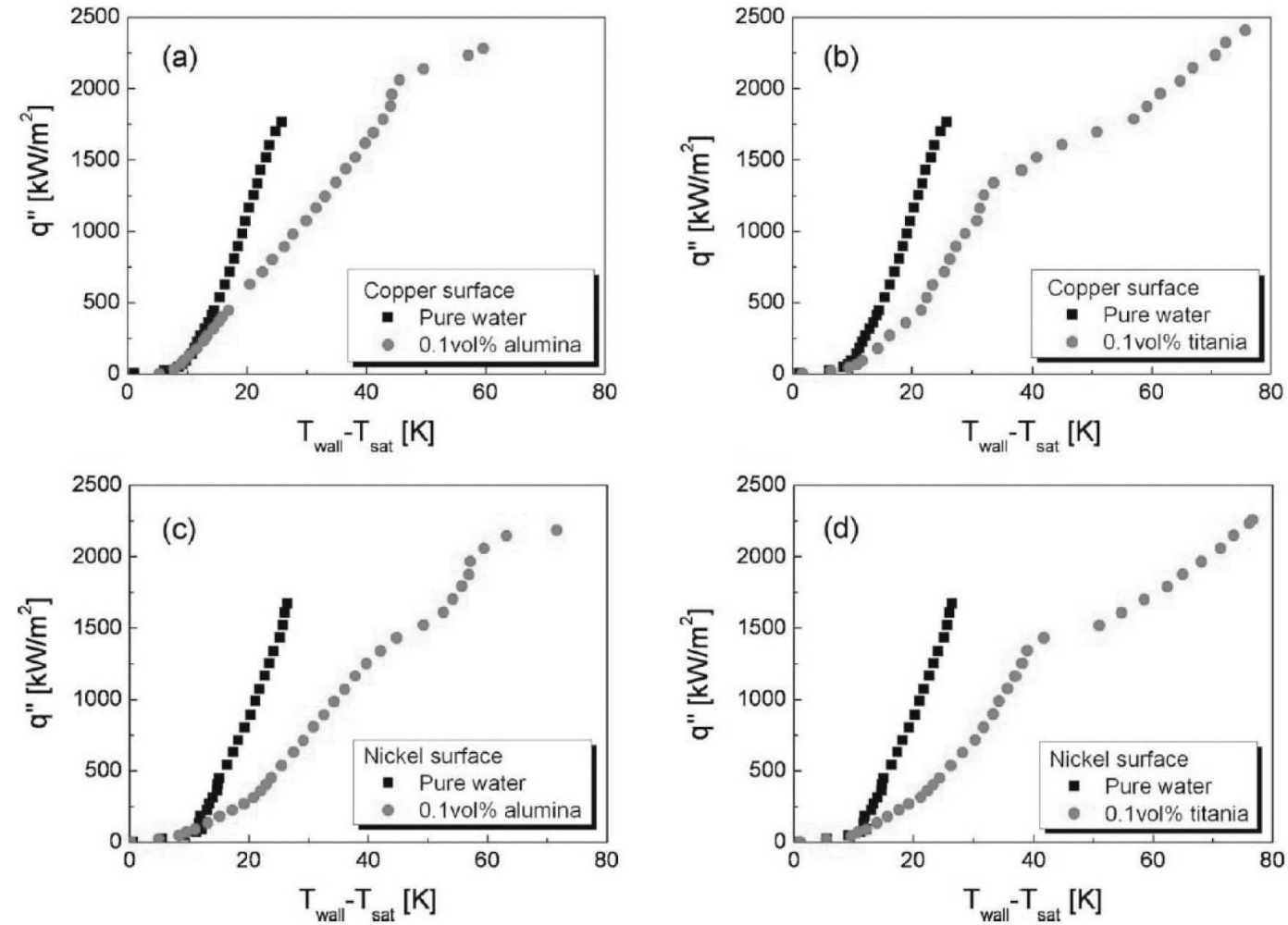

Fig. 3. Boiling Curves for Nanofluids on Plate Heaters: (a) Alumina on Copper; (b) Titania on Copper; (c) Alumina on Nickel; and (d) Titania on Nickel [16].

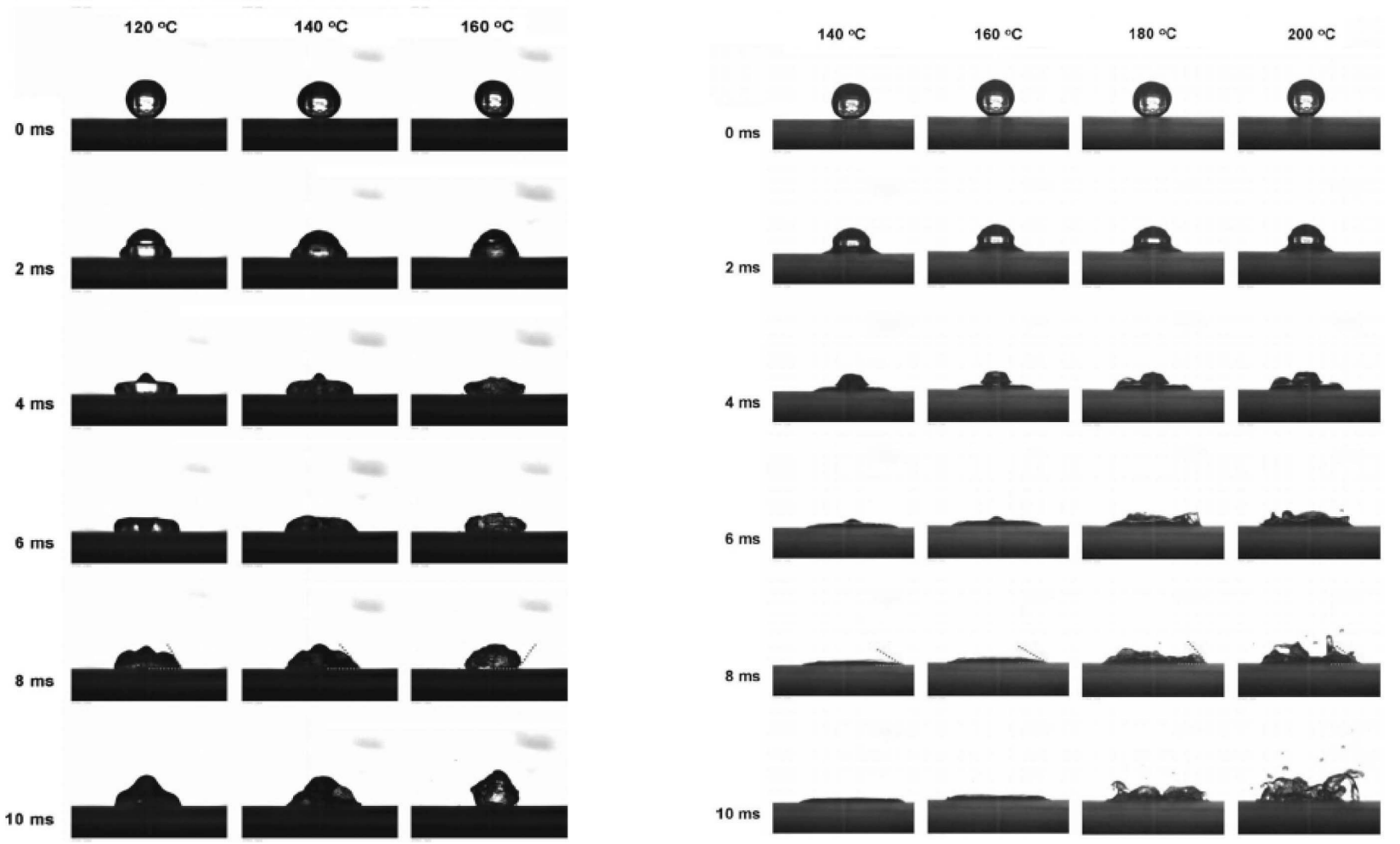

Fig. 4. Wetting of a Water Droplet on a Water Boiled Copper Surface at $120^{\circ} \mathrm{C}, 140^{\circ} \mathrm{C}$ and $160^{\circ} \mathrm{C}$. [16]

Fig. 5. Wetting of a Water Droplet on a Titania Nanoparticlesfouled Copper Surface at $140^{\circ} \mathrm{C}, 180^{\circ} \mathrm{C}$ and $220^{\circ} \mathrm{C}$. [16] 
Thermal heating was used to preclude the effect of electric fields. Detailed information and a schematic diagram are given in Ahn et al. [14]. Aqueous nanofluids with alumina nanoparticles $(0.01 \%$ volume fraction) were investigated. At that volume concentration, a large increase in the CHF was observed during plate-boiling and wire-boiling experiments. The flow-boiling CHF for nanofluids increased significantly during forced convective flow compared with that observed for pure water (Fig. 6). The heating surfaces were then examined using SEM, and the contact angle of droplets was measured (Fig. 7). The results suggest that the flow-boiling CHF increase in nanofluids was mostly caused by nanoparticle deposition on the heater surface during vigorous boiling and by the consequent wettability increases indicated by Fig. 7. Additionally,

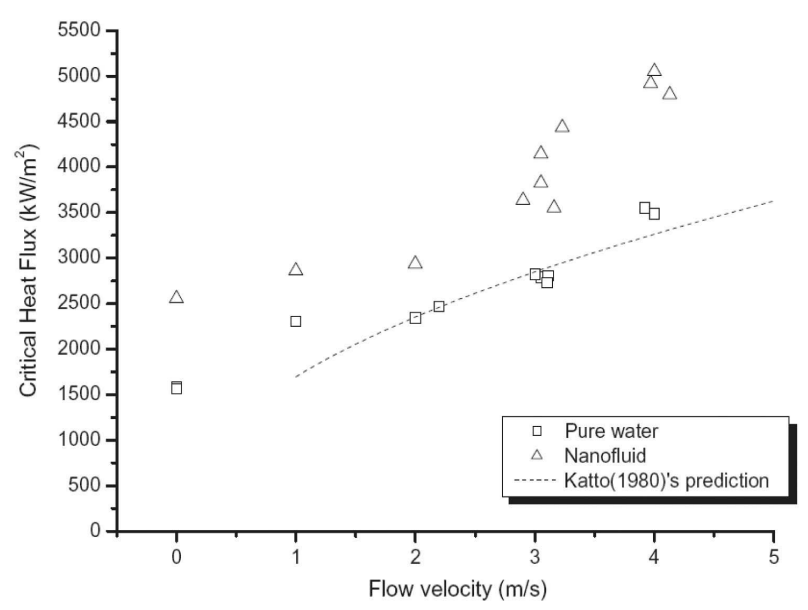

Fig. 6. Critical Heat Flux vs Flow Velocity of Pure Water and Nanofluids. [14]
Ahn et al. postulated that the nanoparticles on the heating surface could be detached during flow boiling due to flow inertia. SEM images and changes in the contact angle revealed that the CHF for a nanoparticle-coated heater in pure boiling water increased less than it did in boiling nanofluids. Ahn et al. [15] used high-speed flow visualization to determine why the CHF increased due to changes in the wettability during flow boiling. The enhanced wettability on the nanoparticle-coated heater delayed the flow-boiling regime compared with that of the bare heater, as shown in Fig. 8. The researchers proposed a new flow-boiling heat-transfer model. However, the nanoparticle-coated heater was not reliable enough to maintain the low contact angle during flow boiling for extended periods of time.

These experimental results indicate that a surface modified by nanoparticle fouling has a significant influence on the large increase in a CHF that is obtained using nanofluids. Among many surface properties, we have concluded that dynamic wetting and liquid capillarity are the most important factors that affect the CHF increase on nanoparticle-fouled heating surfaces.

\section{ARTIFICIAL MICRO/NANOSCALE SURFACE MODIFICATIONS}

\subsection{Micro-, Nano-, and Micro/Nanostructures on Silicon Heater}

Although boiling nanofluids can give a high CHF, they are not appropriate for use in actual heat transfer devices because of problems with aggregation and deposition of the nanoparticles. Therefore, researchers in our lab suggested using MEMS techniques to create an artificial surface that mimics the properties of a nanoparticle-fouled (a)

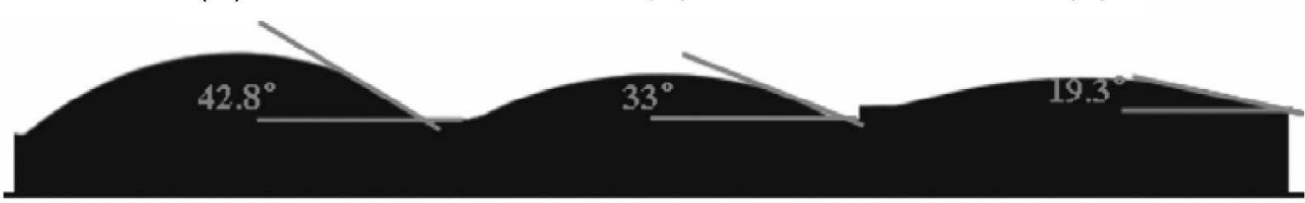

Fig. 7. Contact Angles of Water Droplets on the Nanoparticles-deposited Surfaces at $3 \mathrm{~m} / \mathrm{s}$ CHF: (a) $3638 \mathrm{~kW} / \mathrm{m}^{2}$; (b) 4147 $\mathrm{kW} / \mathrm{m}^{2}$; (c) $4435 \mathrm{~kW} / \mathrm{m}^{2}$. [14]

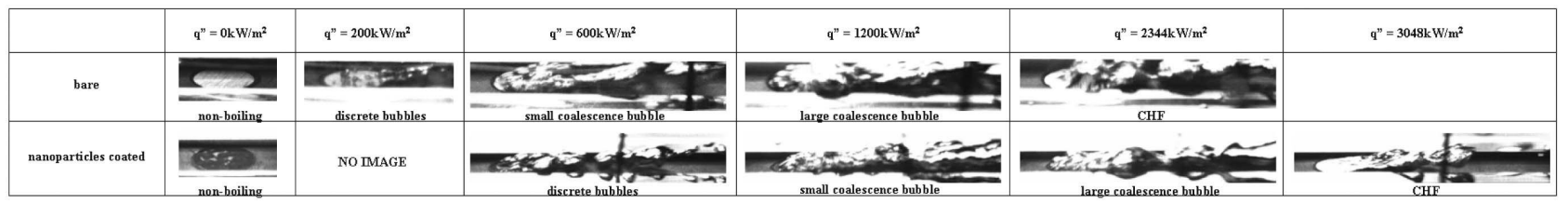

Fig. 8. The Comparison of Flow Boiling Regimes on Bare and Nanoparticles-coated Heaters. [15] 
surface. To facilitate both the CHF test and the surface modification requirements, we embedded a thin-film heater on one side of a silicon wafer and created artificial surfaces on the other side. Although the film heater and surface modifications were fabricated simultaneously, we will describe these processes separately for convenience.

The test heater was fabricated on a rectangular $(25 \times$ $20 \mathrm{~mm}$ ) silicon wafer plate (Fig. 9). Since Joule heating was selected for this experiment, an $\mathrm{SiO}_{2}$ layer for electrical insulation was fabricated on both the top and bottom of the wafer to preclude the possibility of electrical interference on the modified surface structures and on the hydrodynamics on top of the heater. A titanium thin film ( 1000 $\AA$ thick) was layered on the bottom of the substrate using an E-beam evaporator. The completed titanium film heater had an ' $\mathrm{H}$ ' shape. The center bar of the ' $\mathrm{H}$ ', which was the main heat generating area, was $15 \times 10 \mathrm{~mm}$; we confirmed by simple calculation that it generated more than $99 \%$ of the total heat. The vertical bars at ends of the ' $\mathrm{H}$ ' were used for the wire connections. Because it is impossible to connect copper wires to a titanium film using lead solder, an additional gold (Au) film (1500 $\AA$ thickness) was deposited on each vertical bar using the E-beam evaporator. When lead is used to solder Au film on the vertical bars, the bars' resistance becomes smaller than that of the center bar, which ensures that the heat generation is focused in the center bar.

To increase the CHF during pool boiling, the surfaces of the test specimens were modified with microstructures, nanostructures, or micro/nanostructures (Fig. 10). The surface material was $\mathrm{ZnO}$ on a silicon wafer. The detailed procedure and surface characteristics are described in Reference [11].

All experiments were conducted under saturated pool-boiling conditions at atmospheric pressure (101.3 $\mathrm{kPa})$. The applied heat flux ranged from the convective heat-transfer regime to the $\mathrm{CHF}$. An uncertainty analysis of all the data was performed in a previous study [11].

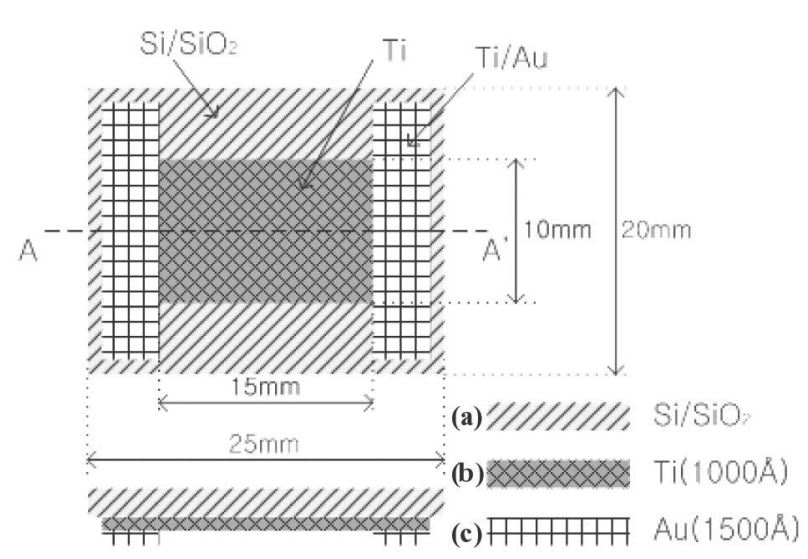

Fig. 9. Test Heater Fabrication of Silicon Surface. [11]
Each modified $\mathrm{SiO}_{2}$ surface showed a noticeable $\mathrm{CHF}$ increase compared with the reference bare surface $(\mathrm{F})$ (Fig. 11). The average CHF was $1121 \mathrm{~kW} / \mathrm{m}^{2}$ for the bare surface, $1652 \mathrm{~kW} / \mathrm{m}^{2}$ for the microstructured surface (M), $2003 \mathrm{~kW} / \mathrm{m}^{2}$ for the nanostructured surface $(\mathrm{N})$, and $2326 \mathrm{~kW} / \mathrm{m}^{2}$ for the micro/nanostructured surface $(\mathrm{MN})$. The CHF estimates for samples with the same surface differed by $<15 \%$. The micro/nanostructured surface showed the greatest increase $(107 \%)$ in CHF compared with the bare surface, followed by the nanostructured surface (79\% increase) and the microstructured surface

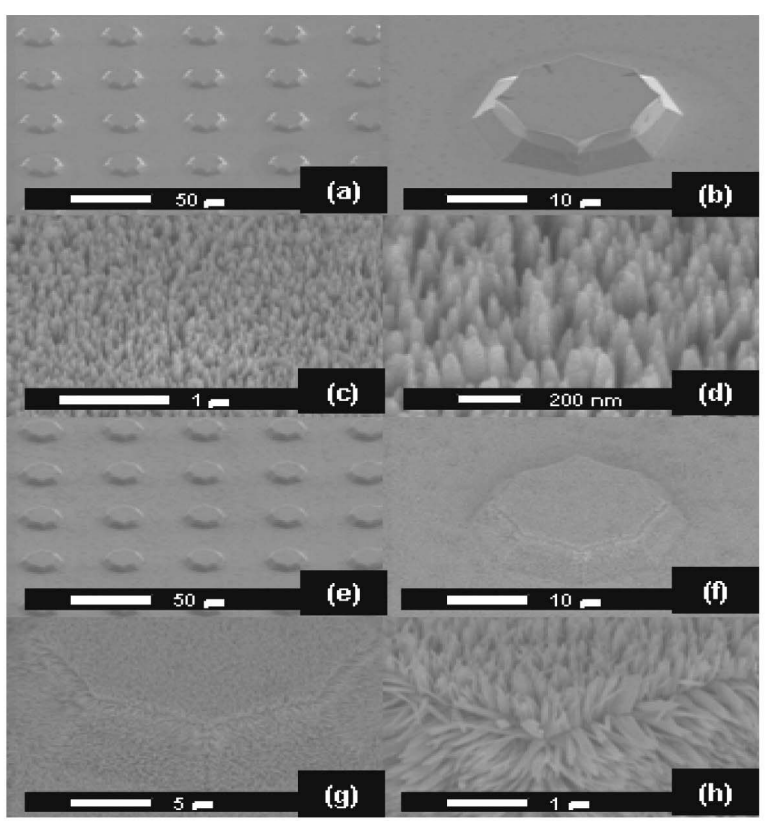

Fig. 10 . Surface Modification by MEMS Fabrication on Silicon Oxide Wafer: (a) and (b) Micro Structured; (c) and (d) Nano Structured; (e), (f), (g) and (h) Micro/Nano Structured. [11]

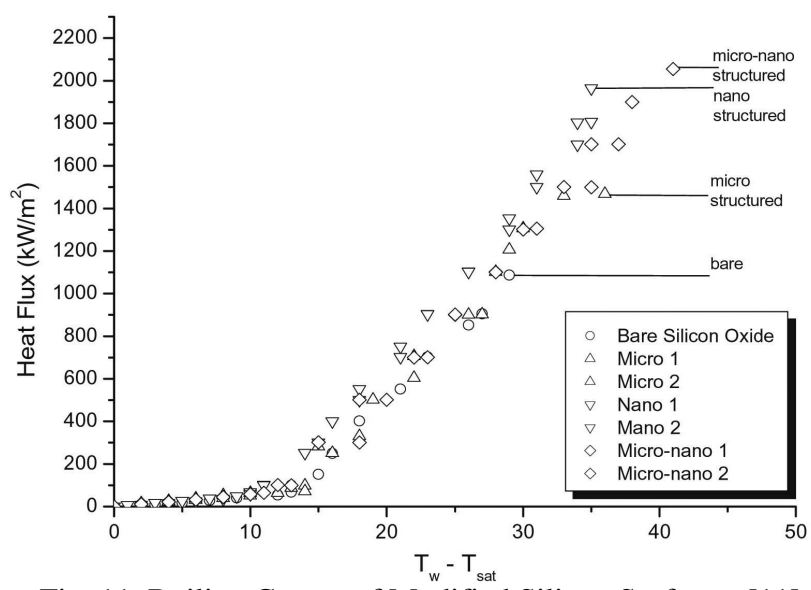

Fig. 11. Boiling Curves of Modified Silicon Surfaces. [11] 
(47\% increase). Therefore, we concluded that the wettability, liquid spreading, and multi-scaled geometry separately affected the CHF increase. The wettability effect was confirmed (Fig. 12) by comparing the results with Kandlikar's CHF correlation [17] (Equation 1), which considers the receding contact angle effect:

$$
\begin{aligned}
q_{\mathrm{CHF}}^{\prime \prime}= & h_{f g} \rho_{\mathrm{g}}^{1 / 2}\left(\frac{1+\cos \beta}{16}\right) \\
& {\left[\frac{2}{\pi}+\frac{\pi}{4}(1+\cos \beta) \cos \phi\right]^{1 / 2}\left[\sigma \mathrm{g}\left(\rho_{l}-\rho_{g}\right)\right]^{1 / 4} }
\end{aligned}
$$

From the experimental results, the wettability and liquid spreading were associated with the CHF increase for nanostructured and micro/nanostructured surfaces. The liquid spreading caused the CHF increase difference between nanostructured and micro/nanostructured surfaces. The multi-scaled geometry caused the difference between the liquid spreading characteristics of the nanostructured and micro/nanostructured surfaces; this indirectly affected the CHF increase [11].

\subsection{Surface Modifications on Zirconium Alloy During Pool Boiling}

We can estimate the effect of the $\mathrm{ZnO}$ surfaces with microstructures, nanostructures, or micro/nanostructures on the CHF. However, the existing technique is not suitable for use in industry because the quality of the modified surface and fabrication method depend on the surface material and the fabrication procedure. Therefore, we developed a surface treatment that is suitable for realistic applications, such as those found in nuclear power plants. Zirconium alloy (Zirlo) was used as the test material for the pool boiling CHF experiments in this study; this material is often used as the cladding for nuclear fuel rods. However, we wanted to enhance the CHF on the

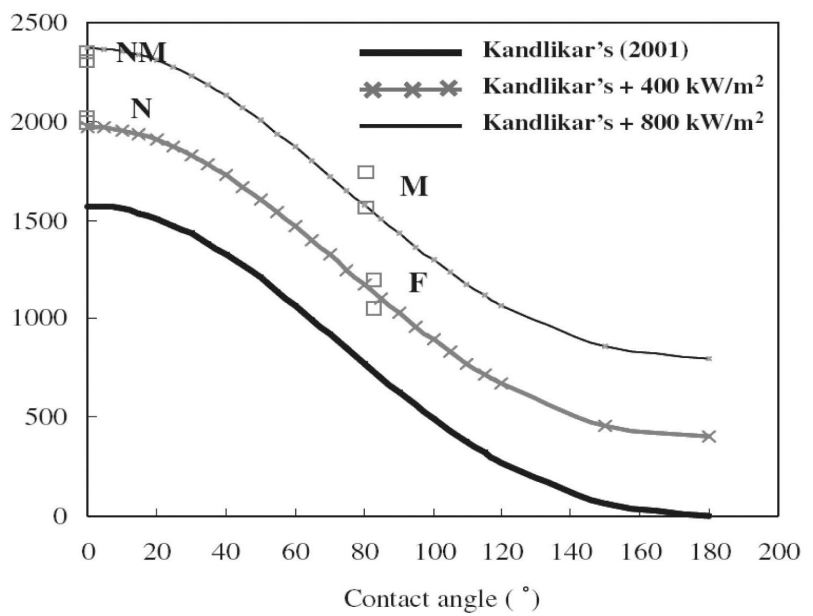

Fig. 12. Plot of CHF Correlation of Kandlikar [16] and Experimental Data of Various Surfaces. [11] zirconium alloy surface by other some method, perhaps using non-traditional metals such as copper or stainless steel. Therefore, we tested various methods of treating the zirconium alloy surface to achieve a more wettable surface.

Anodic oxidation was used to modify the metal surface. This is an electrochemical fabrication technique in which an externally applied electric potential is used to accelerate the chemical reaction at the interface between an electrolyte and the target material. The reaction rate can be easily controlled by adjusting the applied voltage; this control provides a 108-fold increase in the reaction rate per volt of increased potential [18]. Other parameters can also be varied, such as the current density, type of electrolyte, and acid strength, in order to change the reaction, resulting in different end products. The final anodic oxidation product is a generally a thick oxide layer. However, in certain materials and under certain conditions, unique ordered nanostructures occur instead of randomly formed oxide structures; anodic aluminum oxide (AAO) [19] and titania nanotubes [20] are two well-known examples. Because of their nanoporous surface morphologies and the chemical nature of the metal oxide, these examples are very hydrophilic. Anodic oxidation of zirconium alloy has already been attempted, and the results have been observed by microscopy [21]. However, no organized nanostructures have been found, and few studies have attempted to measure the resulting wetting properties.

Zirconia nanotubes have been formed by anodic oxidation [22]. We also succeeded in forming zirconia nanotubes and conducted wettability studies on them as well as on the micro/nanoscale mountain-like structures. Rectangular zirconium alloy plates $(20 \times 25 \times 0.7 \mathrm{~mm})$ were used as test samples. They were mechanically polished with \#1200 silicon carbide abrasive to remove impurities and to produce a uniform surface. The polished samples were cleaned with a 1:1 mixture of acetone and methanol in an ultrasonic bath. After rinsing in deionized water, the samples were completely dried [23]. The detailed anodization process can be found in Reference [12], along with the surface characteristics of the metallic heater shown in Fig. 13.

The boiling curves of the modified zirconium alloy surfaces (Fig. 14) indicated that the nanostructured and micro/nanostructured surfaces had a higher CHF than that of the bare surface or the surface with unorganized structures. Various parameters influenced the CHF directly and indirectly, including the wettability and spreading ability of the surface. Kandlikar [17] analyzed the CHF mechanism using a balance of the recoil force and the surface tension on the heating surface. The recoil force is generated by fast evaporation into the liquid-vapor interface, and the surface tension is provided by a single bubble. He suggested the correlation model given by Eq. 1. However, the CHF increases on the modified surfaces with contact angles $<10^{\circ}$ exceeding those predicted 
considering the wettability effect alone (Fig. 15). Surfaces of modified silicon oxide wafer and modified zirconium alloy were each more wettable and spreadable than the corresponding bare surface. Nanotube-like nanostructures were observed on the zirconium alloy surface (Fig. 13). These nanostructures to some extent increased the ability of the liquid to spread on modified zirconium alloy, and contributed to the $\mathrm{CHF}$ increase. The same surfaces also contained valley-like microstructures (Fig. 13). Microscale structures can increase both the capillary wicking and capillary-driven flow [24]; they can also influence the liquid capillary wicking on the surface [25]. The liquid spreading ability can be characterized by the diameter of the wetted zone that surrounds the liquid droplets [25]. Liquid spreading was observed on the zirconium alloy surfaces with contact angles $<10^{\circ}$, as Figure 16 shows. Therefore, CHF increases that exceeded Kandlikar's correlation could be attributed to the liquid spreading ability on the surfaces. The figure indicates that (a) in the non-spreading regime, the $\mathrm{CHF}$ increased as the contact angle decreased; (b) in the small spreading regime, the

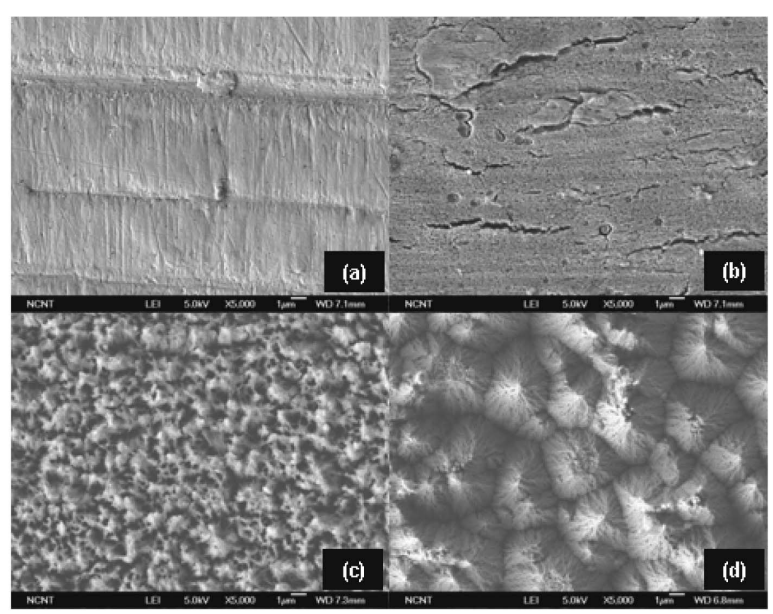

Fig. 13. Surface of Modified Zirconium Alloy: (a) Bare; (b) Oxidized Meaningless Structure; (c) Nano Structure; (d) Micro/Nano Structure.
CHF increase was greater than could be predicted by the wettability effect; and (c) in the large spreading regime, the combination of different micro/nano-multiscale

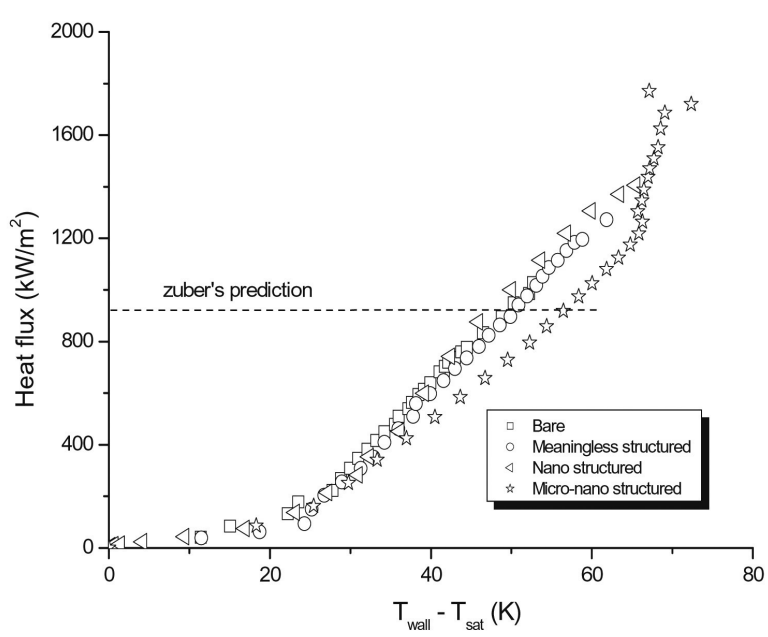

Fig. 14. Boiling Curves of Modified Zirconium Alloy Surfaces. [12]

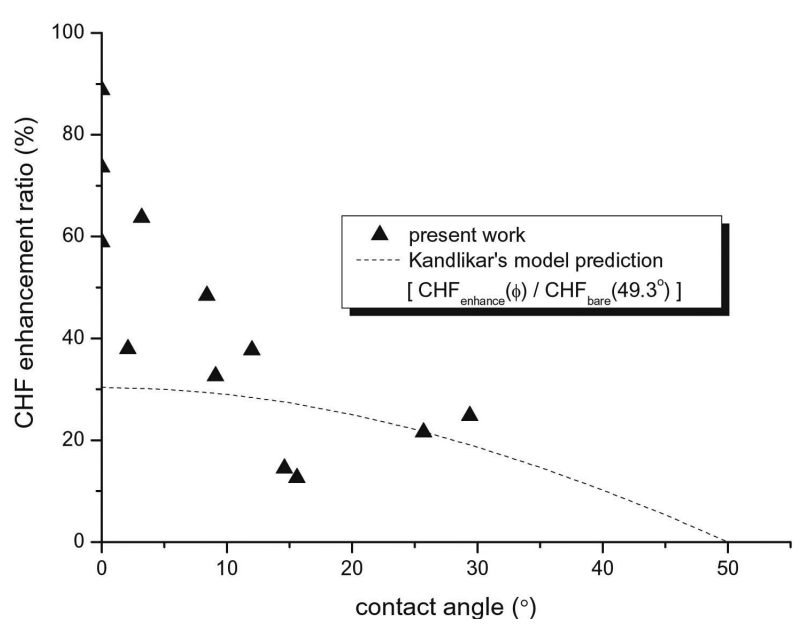

Fig. 15. CHF Enhancement Ratio on the Modified Zirconium Alloy. $\left(\mathrm{CHF}_{\text {enhance }} / \mathrm{CHF}_{\text {bare }}\right)$. [12]

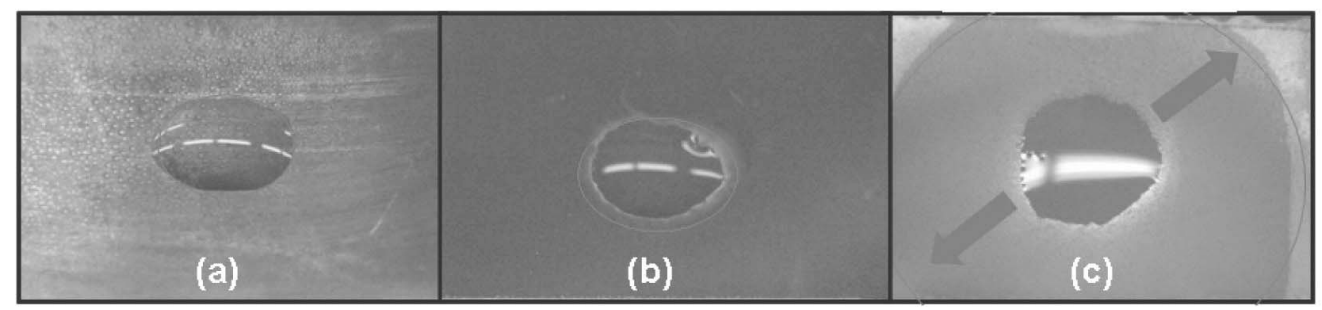

Fig. 16. The Liquid Spreading Abilities of Modified Zirconium Alloy; (a) Non-spreading, (b) Small Spreading and (c) Large Spreading. [12] 
structures on the zirconium alloy surface contributed to a greater $\mathrm{CHF}$ increase than did the individual multiscale structures (Figs. 16 and 17). These results indicate that the surface multiscale structures that caused the contact angle to be $<10^{\circ}$, which had large effects on the liquid spreading ability, were the main contributor to the CHF increase. Kim et al. [11] also reported that nanostructures could facilitate liquid spreading and delay the CHF (Figs. 10 and 11) and that the combination of nanostructures and microstructures had the best liquid spreading ability and the largest $\mathrm{CHF}$ enhancement. Based on these experimental results, we conducted internal pool boiling experiments with modified zirconium alloy surfaces. The results verified the liquid spreading's effect on the CHF enhancement (Fig. 18). As the amount of liquid spreading increased, the CHF increased. The liquid spreading could be controlled by the anodic oxidation time, which indicates that for zirconium alloy, the micro-, nano-, and micro/ nanostructures could also be controlled. Recently, Ahn et al., [26] reported that the effect of the liquid spreading influenced the CHF enhancement which was increased by the liquid supplying on the micro, nano and micro/nano structured surfaces through the optical dynamic wetting test. They quantitatively modeled the heat flux gain of the structural effect (micro, nano, micro/nano structures), which played a role, with the liquid absorbed layer, of supplying the liquid to the dry spot during boiling, finally delaying $\mathrm{CHF}$.

\subsection{Surface Modifications on Zirconium Alloy During Flow Boiling}

POSTECH recently conducted CHF flow-boiling experiments. The experimental facility is illustrated in Fig. 19. The main loop consisted of a pump, flowmeter, pre-heater, steam condenser, heat exchanger, and reservoir. A 3/4" SUS316 tube and fittings made up the entire loop. A centrifugal magnetic gear pump and an inverter were used to circulate the working fluid in the loop. The flow rate was controlled by the throttling valves on the main line and the by-pass line. Two pumps were used; the maximum performance of one was 7 LPM with a 70 bar pressure difference, and that of the other was 14 LPM with a 70 bar pressure difference. Pumps were interchanged depending on the required experimental conditions. To prevent cavitation, the inlet temperature of the pump was maintained in the subcooled regime. The cooling system of the working fluid consisted of a shell-and-tube steam condenser and a plate heat exchanger. The former was a heat exchanger used to condense steam with a small pressure drop; it provided $100,000 \mathrm{kcal} / \mathrm{hr}$ at maximum performance. The plate heat exchanger decreased the temperature of the condensed working fluid before fluid entered the reservoir. A circulation heater acted as the pre-heater so that the temperature of the working fluid was controlled and fixed before fluid entered the test

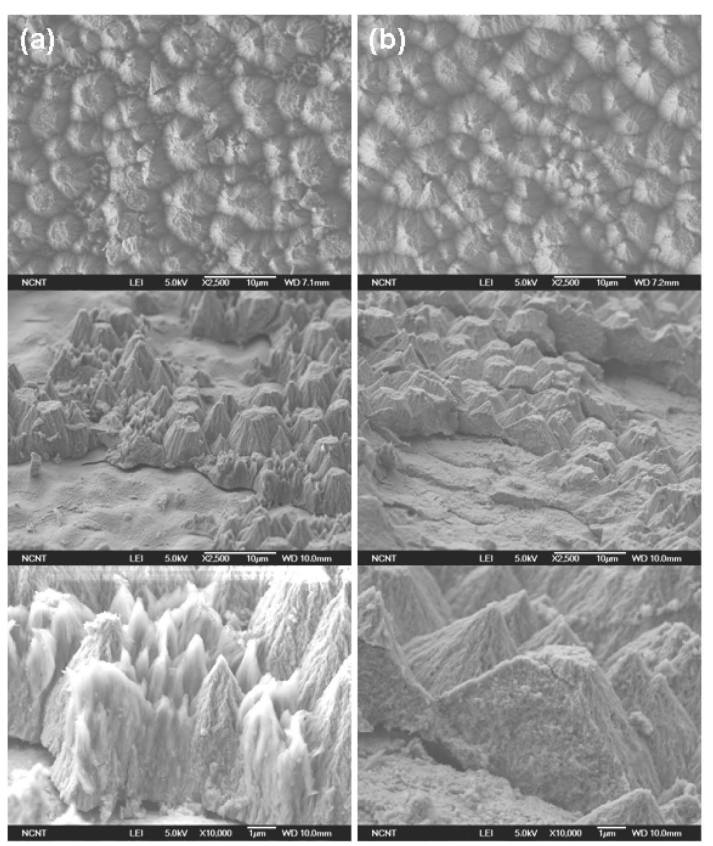

Fig. 17. SEM Images of Large Spreading; (a) CHF: 1924 $\mathrm{kW} / \mathrm{m}^{2}$ (b) CHF: $1770 \mathrm{kw} / \mathrm{m}^{2}[12]$

(a)

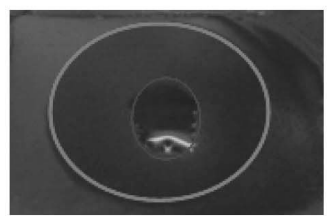

Anodic oxidation time : 10min

CHF enhancement : $72 \%$

(b)

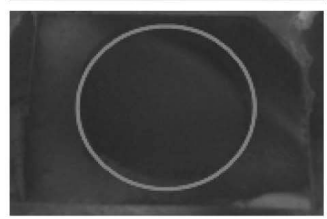

Anodic oxidation time : $8 \mathrm{~min}$

CHF enhancement : $90 \%$

(c)

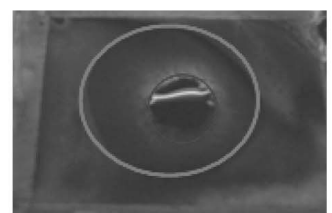

Anodic oxidation time : $6 \mathrm{~min}$

CHF enhance. : $60 \%$

(d)

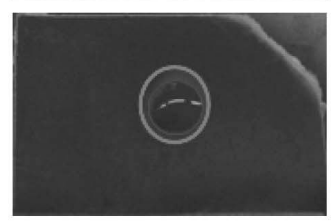

(e)

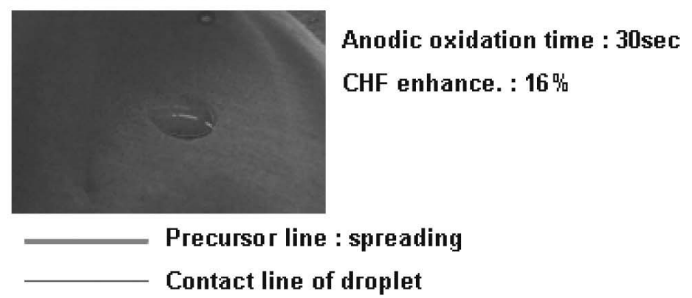

Fig. 18. Liquid Spreading Phenomenon on Modified Zirconium Alloy of Plate. 


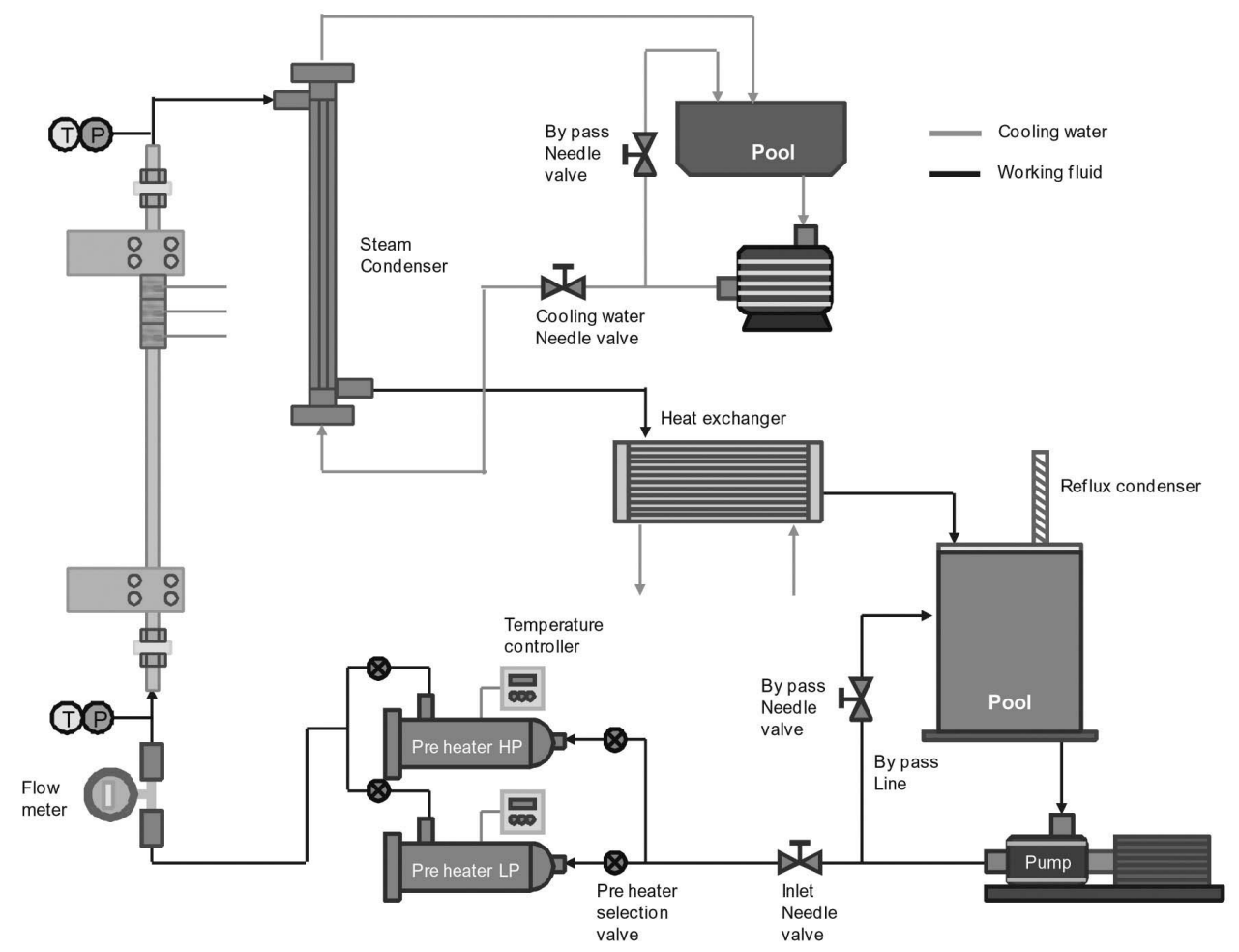

Fig. 19. Schematic Diagram of Internal Flow Boiling Experimental Loop (POSTECH)

section. The outlet temperature of the working fluid from the pre-heater was controlled by a $\mathrm{K}$ thermocouple and a proportional-integral-derivative (PID) temperature controller. A turbine flow meter with a maximum capacity of 10 LPM was used. The pool or reservoir was cylindrical with a $300-\mathrm{mm}$ diameter and a $450-\mathrm{mm}$ depth, and it was placed in front of the pump. The cooling water was tap water. To control the total heat exchanged by the steam condenser and the heat exchanger, a 100-LPM centrifugal pump was installed in the cooling system, which consisted of the large reservoir of tap water and the by-pass line to control the cooling water.

In this study, we conducted an upward internal flowboiling experiment, which means that the flow direction was opposite to the direction of gravity. Joule heating was used, with DC electricity. A $150-\mathrm{kW}$ power supply was used to supply the DC current, which was connected to the specimen (zirconium alloy tube) directly by a machined copper electrode. The temperature and pressure of the inlet and outlet were measured by a thermocouple and pressure transducer. The test specimen was a zirconium alloy tube, which had an outer diameter of $3 / 8^{\prime \prime}$ and a thickness of $0.5 \mathrm{~mm}$. The actual heating length was $430 \mathrm{~mm}$. To measure the surface temperature, 10 thermocouples were installed on the outer surface of the heater with $40-\mathrm{mm}$ gaps between them. The first thermocouple was located $15 \mathrm{~mm}$ from the top of the specimen. A wooden jig was

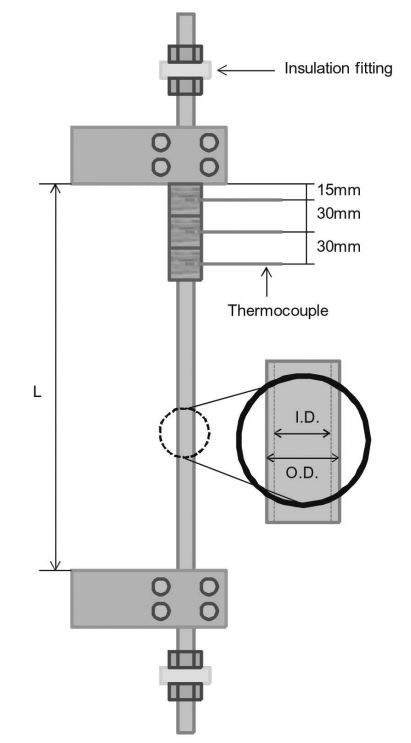

Fig. 20. Schematic of Experimental Test Section of Zirconium Alloy(Zerlo) Tube.

used to attach the thermocouples to the heating surface, as shown in Fig. 20, due to the high wall temperature. Electrical insulation was used to protect the surface from burnout. The insulation also prevented electricity from flowing into the loop. A National Instruments data 
acquisition system and a personal computer were used to collect the data and analyze the temperature and pressure sensors. The information systems were also used to shut down the power supply very quickly, in order to protect the test tube from burnout and explosions when the $\mathrm{CHF}$ was reached.

To conduct the CHF flow-boiling experiments using bare and modified tubes, a special anodic oxidation facility was developed. Through trial and error, suitable conditions were established, and a modified prototype tube was developed, as shown in Fig. 21. The micro/nanostructures were not the same as those used for the pool-boiling experiments; there were micro-valley structures, but these were mostly covered by the oxidation layer. The contact angle of our modified zirconium alloy tube was also less than that of the bare tube, as shown in Fig. 22. The mass flux ranged from $300 \mathrm{~kg} / \mathrm{m} 2 \cdot \mathrm{s}$ to $1500 \mathrm{~kg} / \mathrm{m} 2 \cdot \mathrm{s}$. Figure 23 shows that the $\mathrm{CHF}$ for our modified zirconium alloy increased with the mass flux. Similar to the pool-boiling results with the plate heater, the modified zirconium alloy had increased wettability as a result of microstructures and nanostructures (Fig. 22), but liquid spreading was not observed. This was likely due to the non-optimized anodic oxidation process used. If the anodic oxidation process were optimized, the oxidation layer over the microstructures would disappear, and the liquid would spread on the modified zirconium alloy tube. We plan to identify an optimized oxidation process for modifying the zirconium alloy tube as part of our future work.

\section{CONCLUSION}

Thermal systems that use boiling heat transfer are limited by the $\mathrm{CHF}$ phenomenon and therefore require more efficient heat transfer. Surface effects are important determinants of the $\mathrm{CHF}$. We reviewed methods of increasing the $\mathrm{CHF}$ with nanofluids using surface modifications to alter the surface wettability and liquid spreading ability. In nanofluids research, nanoparticle deposition on a heating surface has been shown to change the surface characteristics (wettability and capillarity) and increase the $\mathrm{CHF}$ in pool and flow boiling. Various investigations have demonstrated that nanoscale structures of nanoparticles on a heated surface strongly influence the CHF enhancement. However, the method of using deposited nanoparticles on the heating surface is not robust enough for real applications. To overcome this problem, we made artificial surfaces with micro- and nanoscale structures that mimicked nanoparticles deposited on a heater. These surfaces showed the same CHF enhancement as those with deposited nanoparticles. We also used artificial surface modification of nuclear fuel material (zirconium alloy) to increase the CHF under pool and flow boiling conditions. The micro-, nano-, micro/nanostructures on the modified zirconium alloy

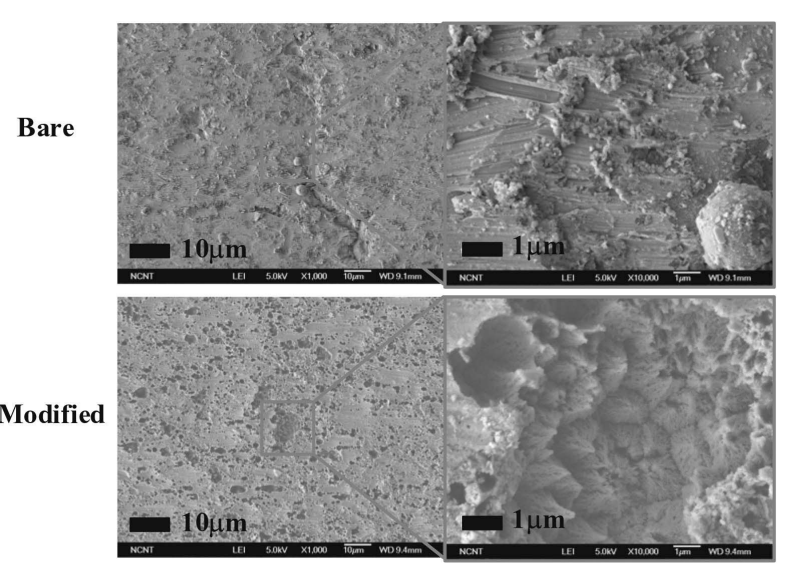

Fig. 21. SEM Images of Bare and Modified Zirconium Alloy Tube Specimen.

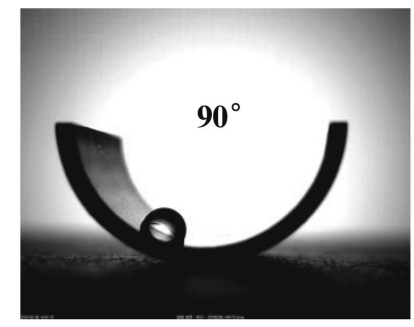

Bare

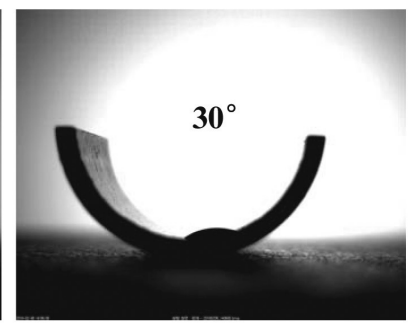

Modified
Fig. 22. Comparison of Contact Angle with Bare and Modified Zirconium Alloy Tube

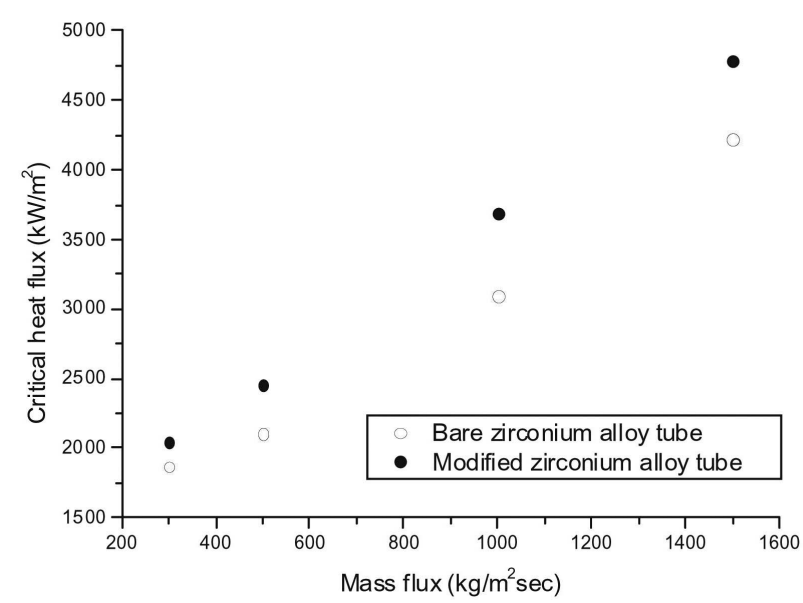

Fig. 23. CHF Enhancement on Modified Zirconium Alloy Tube Under Flow Boiling as Increasing Mass Flux.

increased the CHF due to the good wettability and improved liquid spreading, which actively supplied cooling water to the heating surface due to the capillarity of the surface morphology. 


\section{ACKNOWLEDGEMENTS}

This work was supported by Nuclear Research \& Development Program of the National Research Foundation of Korea (NRF), funded by the Ministry of Education, Science and Technology (MEST) (grant code: MZ07060 00050-08M0600-05010).

This research was supported by the WCU (World Class University) program through the National Research Foundation of Korea, funded by the Ministry of Education, Science and Technology (R31 - 30005)

\section{NOMENCLATURE}

q" Heat flux $\left(w / \mathrm{m}^{2}\right)$

$\mathrm{h}$ Latent heat $(\mathrm{kJ} / \mathrm{kg})$

g Acceleration of gravity $\left(\mathrm{m} / \mathrm{s}^{2}\right)$

\section{Greek letters}

$\sigma \quad$ Surface tension $(\mathrm{N} / \mathrm{m})$

$\rho \quad$ Density $\left(\mathrm{kg} / \mathrm{m}^{3}\right)$

\section{Subscripts}

$l \quad$ Liquid state

$g \quad$ Vapor state

\section{REFERENCES}

[1] Choi, S.U.S., 1995 Enhancing thermal conductivity of fluids with nanoparticles, developments and applications of non-Newtonian flows, FED-Vol. 231/MD-Vol. 66.

[2] You, S.M., Kim, J.H., and Kim, K.H., 2003, Effect of nanoparticles on critical heat flux of water in pool boiling heat transfer, Appl. Phys. Lett. 83, pp. 3374-3376.

[3] Kim, H.D., Kim, J. and Kim, M.H., 2006, Effect of nanoparticles on CHF in pool boiling of nano-fluids, Int. J. of Heat and Mass Transfer, 49, pp. 5070-5074.

[4] Golobic, I. and Ferjancic, K., 2000, The role of enhanced coated surface in pool boiling CHF in FC-72, Heat and Mass Transfer, 36, pp. 525-531.

[ 5 ] Kim, H.D. and Kim, M.H., 2007, Experimental studies on CHF characteristics of nano-fluids at pool boiling, Int. J. Multiphase Flow, 33, pp. 691-706.

[6] Liu, Z. and Liao, L., 2008, Sorption and agglutination phenomenon of nanofluids on a plane heating surface during pool boiling, Int. J. Heat Mass Transfer, 51, pp. 2593-2601.

[ 7 ] Coursey, J.S. and Kim, J., 2008, Nanofluid boiling: The effect of surface wettability, Int. J. Heat Fluid Flow, 29, pp. 1577-1585.

[ 8 ] Kim, H.D. and Kim, M.H., 2007, Effect of nanoparticle deposition on capillary wicking that influences the critical heat flux in nanofluids, Appl. Phys. Lett., 91, pp. 014104.

[ 9 ] Takamasa, T., Hazuku, T., Okamoto, K., Mishima, K., and Furuya, M., 2005, Radiation induced surface activation on Leidenfrost and quenching phenomena, Experimental
Thermal and Fluid Science, 29, pp. 267-274.

[10] Dhir, V. K., 1998, Boiling heat transfer, Annual Review of Fluid Mechanics, 30, pp. 365-401.

[11] Kim, S.T., Kim, H.D., Kim, H., Ahn, H.S., Jo, H.J., Kim, J., and Kim, M.H., 2010, Effects of nano-fluid and surfaces with nano structure on the increase of CHF, Experimental Thermal and Fluid Science, 34, pp. 487-495.

[12] Ahn, H.S., Lee, C., Kim, H., Jo, H.J., Kang, S.H., Kim, J., and Kim, M.H., 2010, Pool boiling CHF enhancement by micro/nanoscale modification of Zircaloy-4 surface, Nuclear Engineering and Design, 240, pp. 3350-3360.

[13] Jeong Y.H., Sarwar M.S., and Chang S.H., 2007, Flow boiling CHF enhancement with surfactant solutions under atmospheric pressure, 51, pp. 1916-1919.

[14] Ahn, H.S., Kim, H., Jo, H.J., Kang, S.H., Chang, W.P., and Kim, M.H., 2010, Experimental study of critical heat flux enhancement during forced convective flow boiling of nanofluid on a short heated surface, Int. J Multiphase Flow, 36, pp. 375-384.

[15] Ahn H.S., Kang S.H., Jo H.J., Kim H, and Kim M.H., 2010, Visualization study of the effects of nanoparticles surface deposition on convective flow boiling CHF from a short heated wall, Int. J. Multiphase Flow, in press.

[16] Kim H., Ahn H. S., and Kim M. H., On the mechanism of pool boiling critical heat flux enhancement in nanofluids, J. Heat Transfer 132, pp. 061501.

[17] Kandlikar, S.G., 2001, A theoretical model to predict pool boiling CHF incorporating effects of contact angle and orientation, J. Heat Transfer 123, pp. 1071-1079.

[18] Soriaga and Manuel, P., Electrochemical Surface Science, 1988, American Chemical Society, pp. 1.

[19] Ono, S., Saito, M., and Asoh, H., 2005, Self-ordering of anodic porous alumina formed in organic acid electrolytes, Electrochemica Acta, 51, pp. 827-833.

[20] Gong, D, Grimes, G.A., and Varghese, O.K., 2001, Titanium oxide nanotube arrays prepared by anodic oxidation, Journal of Material Research, 16, pp. 3331-3334.

[21] Ploc, R.A. and Miller, M.A., 1977, Transmission and scanning electron microscopy of oxides anodically formed on zircaloy-2, Journal of Nuclear Materials, 64, pp. 71-85.

[22] Lee, W.J. and Smyrl, W.H., 2008, Oxide nanotube arrays fabricated by anodizing processes for advanced material application, Current Applied Physics, 8, pp. 818-821.

[23] Salot, R., Lefebvre-Joud, F., and Baroux, B., 1996, Electrochemical behavior of thin anodic oxide films on zircaloy-4: role of the mobile defects, Journal of Electrochemistry Society, 143, pp. 3902-3909.

[24] Chen, Y., Melvin, L.S., Weislogel, M.M., Jenson, R.M., Dhuey, S., and Nealey, P.F., 2008, Design, fabrication, and testing of micro porous wicking structure, Microelectronic Engineering, 85, pp. 1027-1030.

[25] Ishino, C., Reyssat, M., Reyssat, E., Okumura K., and Quere D., 2007, Wicking within forests of micropillars, Europhysics Letters, 79, pp. 56005.

[26] Ahn, H.S, Jo, H.J., Kang, S.H., and Kim, M.H., 2011, Effect of liquid spreading due to nano/microstructures on the critical heat flux during pool boiling, Applied Physics Letters, 98, pp. 071908. 